\title{
Acoustic data and recognition in short-term-memory'
}

VICKI PEARTHREE, DAVID S. GORFEIN AND RAYMOND W. BENHETT

A system for selecting altematives to be used in STM recognition studies is suggested based on the use of acoustic confusions made by Ss on hearing their own pronunciations. The system produces credible multiple choice alternatives with specifiable relative probabilities of being selected. It is also clear from the data that factors other than the acoustic coding of items plays an important role in short-term retention.

One of the basic problems in using recognition as a measure of retention is that recognition is very sensitive to differences in the set of alternatives from which an individual must choose the correct item. Murdock (1963, p. 20) suggests that recognition memory is completely dependent upon the probability of eliminating incorrect alternatives.

While recognition memory has been used in a number of short-term-memory (STM) studies, no one has yet suggested a system for selecting suitable alternatives to the correct choice. Since it has now been amply documented (Conrad, 1962, 1963, 1964; Conrad, Freeman, \& Hull, 1965; Wickelgren, 1965a, b, c, d, $1966 \mathrm{a}, \mathrm{b})$ that acoustic confusions play a major role in STM, the present investigators examined the effect of using Ss' acoustic confusions in decoding a taperecording of their own voice as alternatives in a multiple choice recognition test of STM.

Method

Twenty-six New College students were paid volunteers for the development of the "spell" score. In this phase of the study Ss were shown a single item at a time projected with a Kodak Carousel projector and were asked to pronounce the item as quickly as possible. A tape-recording was made of each $\mathrm{S}$ pronouncing the items and upon completion of the pronunciation task, the tape was played back to $S$ continuously and he was asked to write each syllable as he decoded it from his pronunciation. Thirty-nine CCC syllables of $50 \%$ association value (Witmer, 1935) were used to form the basis for a "spell" score which was computed by dividing the number of correctly decoded responses to a particular syllable by the total number of responses to that syllable by all Ss. The proportion of each wrong decoding to the total was also calculated.

The recognition study. For each of the $39 \mathrm{CCCs}$ five alternatives to the item were selected employing the five incorrect decodings with the highest proportions of choice. Together with the correct alternative we then had six choices for each item in a multiple choice format. Items were then arranged in a random order with the restriction that consecutive items did not have the same consonant in the same position.

Each CCC was then presented visually using the standard Peterson \& Peterson (1959) method with an $18 \mathrm{sec}$. retention interval. S pronounced the item when presented. When the recall signal was given he turned over the next card in a pack of index cards that gave the six alternatives in random order and selected his choice. Recall period was $10.5 \mathrm{sec}$. Thirty-five paid volunteers from the New College student body participated. All had taken part in a previous STM study.

For the purposes of analysis of the data the last $35 \mathrm{CCCs}$ were used, since it has been demonstrated (Melton, 1963) that proactive inhibition builds up over the first few items to a steady state.

Results

The mean "spell" score (proportion of correct spelling of items) was .2660 with a standard deviation of .1677.

Errors per item in short-term-memory ranged from one to 19 with a mean of 8.2 and standard deviation of 4.73 . The "spell" score correlated significantly with the number of errors made per item in short-term memory $(r=-.37, t=2.32, p<.05)$.

For the incorrect alternative provided on the recognition test we computed for each item the proportion of times it was emitted in the "spell" standardization for the population of 175 incorrect alternatives. A correlation was then run between this proportion and the number of times the alternative had been chosen in the short-term-memory experiment. This correlation was $.21(t=2.38, p<.01)$.

Since the alternatives for a given item were quite often equally probable (.20 each) we chose from the 35 items the 10 items whose five alternatives encompassed at least three levels of probability. These 50 alternatives were then correlated with their respective errors. The obtained correlation was .39 $(t=2.96, p<.01)$.

\section{Discussion}

Considering the myriad factors that enter into S's selections in a multiple choice test and the restriction on range in the data (in terms of the small number of incorrect guesses) the obtained correlations are quite large. The "spell" measure therefore produces believable alternatives with specifiable probabilities. The data clearly support the feasibility of using de- 
coding attempts as the alternatives in a recognition measure of STM since less than $15 \mathrm{hr}$. in data collection time are necessary for obtaining the alternatives.

It had been anticipated on the basis of the acoustic confusion literature that the proportion of errors made by $S$ on a particular item would be about equivalent to the proportion of errors on the "spell" measure. However, while the "spell" scores had a mean proportion of .2660 correct, the Ss actually averaged .7657 correct recognitions. Part of the difference can undoubtedly be attributed to the reproduction quality of the tape recording in the "spell" group and part to the elimination of some of the alternatives emitted in the "spell" group in order to get down to the six alternative multiple choice situation. The second factor accounts for .1309 of the difference, as the mean proportion of "spell" based on the alternatives used in the last 35 items is .3969 . Beyond this, however, it is well to recognize, based on our data, that a signiflcant amount of retention in STM is dependent on factors other than acoustic coding since Ss are better at decoding from STM than from the sound of their own roices.

\section{References}

Conrad, R. Acoustic confusions and memory span for words. Nature, 1963, 197, 1029-1030.

Conrad, R. An association between memory errors and errors due to acoustic masking of speech. Nature, 1962, 193, 1314-1315.
Conrad, R. Acoustic confusions in immediate memory. Brit. J. Psychol., 1964, 55, 75-84.

Conrad, R., Freeman, P. R., \& Hull, A. J. Acoustíc factors versus language factors in short-term memory. Psychon. Sci., 1965, $3,57-58$.

Melton, A. W. Implications of short-term memory for a general theory of memory. J. verbal Learn. verbal Behav., 1963, 2, 1-21.

Murdock, B. B., Jr. An analysis of the recognition process. In C. Cofer \& B. Musgrave (Eds.), Verbal behavior and verbal learning. New York: McGraw-Hill, 1963.

Peterson, L. R., \& Peterson, M. J. Short-term retention of individual verbal items. J. exp. Psychol., 1959, 58, 193-198.

Wickelgren, W. A. Short-term memory for phonemically similar lists. Amer. J. Psychol., 1965, 78, 567-575.

Wickelgren, W. A. Distinctive features and errors in short-term memory for English vowels. J. Acoust. Soc. Amer., 1965, 38, 583-589.

Wickelgren, W. A. Acoustic similarity and intrusion errors in shortterm memory. J. exp. Psychol., 1965, 70, 102-108.

Wickelgren, W. A. Acoustic similarity and retroactive interference in short-term memory. J. verbal Learn. verbal Behav., 1965, 4, 53-61.

Wickelgren, W. A. Distinctive features and errors in short-term memory for English consonants. J. Acoust. Soc. Amer., 1960, 39, 388-398.

Wickelgren, W. A. Phonemic similarity and interference in shortterm memory for single letters. J. exp. Psychol., 1966, 71, 396405 .

Witmer, L. R. The association value of three-place consonant syllables. J. genet. Psychol., 1935, 47, 337-360.

\section{Note}

1. This research was supported in part by an Academic Year Extension grant under the National Science Foundation Program for Research Participation by College Teachers to D. S. Gorfein. 